Artículo de investigación

Cuestiones de filosofía

ISSN: 0123-5095

Vol. 2 - No. 19

Julio - diciembre, año 2016

pp. $173-202$

\title{
La noción de creación deleuziana en la elaboración de material didáctico en lenguas extranjeras*
}

\author{
Deleuze's notion of creation applied to the production \\ of didactic resources for foreign language teaching
}

\author{
Martha Pardo-Segura** \\ Universidad Pedagógica y Tecnológica de Colombia
}

Fecha de recepción: 7 de mayo del 2016

Fecha de evaluación: 3 de julio del 2016

Fecha de aceptación: 15 de septiembre del 2016

* Línea: Saberes pedagógicos. Grupo de investigación J.O.I.E.: Jeu. Organisation. Interculturalité. Enseignement. Proyecto Investigación y creación: elaboración de material didáctico para la enseñanza del francés de educación básica rural en Boyacá. Convocatoria Capital semilla SGI 1522. CIEFED-DIN-UPTC. joiedelallanguefrançaise@uptc.edu.co; martha.pardo@uptc.edu.co

** Coordinadora académica del Doctorado en Lenguaje y Cultura (2015-2016), docente investigadora de la lengua, la cultura y la literatura francesas y francófona. Doctorado en Literatura y Civilización francesas, Paris III pardoseguramartha@yahoo. f. Calle $98 \mathrm{~N}^{\circ} 19^{\mathrm{a}}$ 79 Bogotá. "L'interculturel à la porté des enfants colombiens" (2016) FIPF. Lisons en langue française. Cinq auteurs français parlent aux enfants (2015). UPTC: "Pedagogía de la acción en ambientes radiales para la enseñanza y el aprendizaje del francés" (2018) Lenguaje, Vol. $40 \mathrm{~N}^{\mathrm{o}} 2$. 


\section{Resumen}

El objetivo de este artículo es mostrar el resultado del proyecto Investigación y creación de material didáctico en francés, basado en la noción deleuziana de “acto creador" y en aquella de investigación en creación de Schön (1994) asociadas a la reflexión sobre la acción. Este acto de resistencia deleuzianano obedece la distancia entre el investigador, el practicante y el artista porque ella alude al deber ser de un docente de lenguas extranjeras según Laurier y Lavoie en el salón de clase por cuanto un maestro está en el lugar y a la hora del entorno del niño. Con el enfoque cualitativo de investigación de tipo etnográfico se desarrollaron cuatro etapas basadas en la descripción de la vida real y del comportamiento del actor social en su medio rural: etapa I (2012): Processus de création d'un manuel d'apprentissage du français à l'école de la zone rurale du département de Boyacá; etapas II y III (2013-2014): traducción y adaptación del corpus original del castellano al francés, diseño de las actividades pedagógicas apoyadas e ilustradas con el corpus visual recolectado en la etapa I y ampliado en la etapa II de la investigación ; etapa IV: correspondencia entre los aspectos pedagógicos y los fundamentos teóricos de la investigación y creación del manual. Los resultados señalan la capacidad y competencia creadora de los futuros docentes de lenguas extranjeras, materializadas en el machote del libro Vive la joie en Français.

Palabras clave: Investigación en creación, material didáctico, francés.

\section{Résumé}

Le but de cet article est de montrer les résultats du projet Recherche et créationdu matériel didactique en français sur la base de la notion de Deleuze d'acte créateur et celle de recherche en création de matériel didactique de Schön (1994) associées à la réflexion sur l'action. Cet acte de résistance deleuzienne n'observe pas de distance entre le chercheur, le praticien et l'artiste parce qu'elle fait allusion au devoir être d'un enseignant de langues étrangères selon Laurier Lavoie dans la salle de classe puisqu'il se trouve dans le lieu et l'heure de l'environnement de l'enfant. Avec l'approche de la recherche qualitative de type ethnographique, quatre étapes se sont développées à partir de la description de la vie et le comportement 
de l'acteur social dans les zones rurales. Phase I (2012): Processus de création du manuel d'apprentissage du français à l'école de la zone rurale du département de Boyacá ; Phases II et III (2013-2014): traduction et l'adaptation du corpus original de castillan au français, mise en forme conceptuelle d'activités pédagogiques soutenues et illustrées par le corpus visuel recueillis dans les phases I et II des recherches plus approfondies; Phase IV: correspondance entre les aspects pédagogiques et les fondements théoriques de la recherche et de la création. Les résultats montrent la capacité créatrice et la compétence des futurs enseignants de langues étrangères, matérialisée dans le formatdu livre Vive la joie en Français.

Mots clé: Recherche en création, matériel didactique, français.

\begin{abstract}
The main of this article is to show the results of the Research and creation of didactic material project, based on Deleuze's notion of creative act and that of Schön's research in creating (1994) associated with reflection on action. This act of Deleuze resistance does not observed distance between the researcher, the practitioner and the artist because she refers to what should be a teacher of foreign languages according to Laurier and Lavoie in front of his duty to be in the classroom because the teacher is at the place and on the time of the child's environment. With the qualitative research and the ethnographic approach, four stages based on the description of real life and behaviour of the social actor in its rural areas were developed:stage I (2012): the process of creating a learning manual of French in rural school of the department of Boyacá; stages II and III (2013-2014): translation and adaptation of the original corpus of Castilian to French, shape design of educational activities supported and illustrated in visual corpus collected in stages I and II of the expanded research; Stage IV: correspondence between the pedagogical aspects and the theoretical foundations of the research and creation of the manual. The results show the creative capacity and competence of future teachers of foreign languages, materialized in the form used by the book Vive la joie en Français.
\end{abstract}

Key words: Educational Research, teaching materials, french. 


\title{
INTRODUCCIÓN
}

\author{
Solo el acto de resistencia resiste a la muerte, \\ sea bajo la forma de obra de arte, \\ sea bajo la forma de una lucha de los hombres. \\ Gilles Deleuze, 1986
}

El filósofo francés Gilles Deleuze ha sido uno de los pensadores del siglo XX, destacado por abordar la ciencia, la filosofía y las diversas disciplinas del conocimiento humano como un "acto creador" originado en una necesidad del ser. En nuestro caso, esta concepción de creación está ausente en la linguiística aplicada a la enseñanza de los idiomas. Dicha carencia se origina en la acción intelectual misma por cuanto el maestro de lenguas extranjeras está expuesto a su imperfección como límite de sus acciones creativas. La penuria viene además de los límites de dar cuenta de nociones filosóficas que rodean el quehacer docente frente a la creación; si no es recurriendo a sus saberes previos tanto pedagógicos, didácticos, en algunos casos, como a los de la literatura, en otros, el docente de idiomas está desprovisto del "acto creador".

Con este límite, aparece la necesidad de recurrir a Gilles Deleuze para entender la tendencia actual de hablar de investigación y creación. Esta necesidad se sitúa en la temporalidad y espacialidad de la formación de maestros del lenguaje, de las lenguas y las culturas. Investigación y creación es una pareja de vocablos que se encuentran en la acción del maestro; él cuestiona si las dos nociones tienen puntos en común. De las experiencias observadas, surgió la idea de escuchar una de las conferencias dictadas por Gilles Deleuze, pronunciada en la Fundación de oficios de la imagen y del sonido en Paris, el 2 de julio de 1987, bajo el título ¿Qué es el acto de creación? (Deleuze, 1987, pp. 1-2)

La noción deleuziana del acto de creación en la elaboración de material didáctico en lenguas extranjeras se presenta como pertinente para resolver uno de los problemas prácticos que se ha diagnosticado año tras año por los docentes y practicantes de la licenciatura en lenguas extranjeras, la escasez de material didáctico que fortalezca la voluntad política de reintroducir el francés en Colombia en las instituciones educativas. Se manifiestan asílas preguntas de investigación: ¿De qué manera el acto de creación deleuziana se aproxima al proceso de investigación cualitativa? ¿Qué elementos de la noción de creación y la de investigación entran 
en movimiento productivo común para disponer la intención de "hacer devenir la materia de contenido en materia de expresión" pedagógica intercultural para enseñar el francés?

La repuesta a estos interrogantes tiene como objetivo mostrar el "movimiento productivo" que trazó el itinerario del conjunto de materias de expresión estéticas el cual "se desarrolló en "motivos" y en "paisajes territoriales" (U’wa, Rural, Boyacá); estos se encontraron tanto en el "proceso como en lo creado" (Díaz, 2012, pp. 6-7) con fines pedagógicos: el manual de francés, la obra literaria de relatos de las tradiciones U’wa, la reflexión teórica del uso de material hecho en madera.

Esta investigación sobre el acto de creación de material didáctico en lenguas extranjeras pasó por tres momentos. El primero presenta la utilidad de la noción del acto de creación deleuziana en el campo específico de la formación en lenguas extranjeras. El segundo introduce la investigación y creación como teoría reciente del proceso que apoya la relación entre el saber teórico y la práctica de ese saber, a partir de la experiencia propia en el campo pedagógico (Daza Hurtado \& Muñoz Talero, 2014, p. 24). Y el tercer momento trató de la pragmática de estas nociones en la creación de material didáctico de enseñanza de la lengua extranjera que Gilles Deleuze representa como uno de tantos hablantes nativos nacido en Paris el 18 de enero de 1925.

\section{El ACTO DE CREACión DELEUZiana}

Gilles Deleuze plantea el acto de creación a partir de la pregunta sobre qué es tener una idea en algo. "Tener una idea no es algo general, no es algo corriente; es más bien "un acontecimiento raro, una especie de fiesta" (Deleuze, 1987, p. 1). Para él, una idea está "ya vista de antemano", "está ya en tal autor", "en un dominio determinado". Una idea no es lo mismo en cine, en artes plásticas, en literatura, en ciencia o en filosofía. Una idea se trata como "un espacio potencial", "comprometida y ligada con un modo de expresión determinado". Por ello, para este filósofo francés, decir "tener una idea general" no es posible porque este acto surge "en función de las técnicas" que el creador o productor emplee para "[tener] una idea en un determinado campo", "una idea en cine [es] "bien distinto de una idea en filosofía".

Deleuze define la filosofía como una disciplina creadora e inventiva como cualquier otra disciplina", poseedora de "su propio contenido". "La filosofía es una disciplina 
que consiste en crear conceptos". Para Deleuze, "los conceptos no existen ya hechos", ni situados en un lugar en donde esperan ser tomados. Es necesario que un sujeto los fabrique. El hacer un concepto o un cuadro o una obra literaria o un libro de lectura nace de la existencia de una necesidad. Esta necesidad, que es compleja, "hace que un filosofo" como Deleuze "se ocupe de inventar, crear conceptos", porque es su dominio. Así entonces, una creación una producción de algo deviene de una necesidad del investigador o del creador en el dominio en que cada uno se desarrolla. Los ejemplos deleuzianos de este modo de crear se refieren al cineasta quien se ocupa de "inventar bloques de movimiento-duración", al pintor que inventa con "bloques de punto-'línea-color", al músico que fabrica con "bloques de" estribillos o de "refranes musicales" y los asemeja a la ciencia que es tan creadora como los dominios citados. Deleuze afirma que no ve oposición entre la ciencia, las artes y todo lo que implica el hacer a partir de una necesidad.

Es a partir de esta presentación del acto de creación que Deleuze aborda el caso del sabio científico quien, para este filósofo, inventa, no descubre. Deleuze escribe:

Un científico, inventó, creó tanto como un artista. Un científico es alguien que crea o inventa funciones. Él no crea conceptos, un científico como tal, no tiene nada que ver con los conceptos, y es por eso que felizmente existe la filosofía. Contrariamente hay algo que sólo un científico puede hacer, crear e inventar funciones. (Deleuze, 1987, p. 2)

De manera comprensible para los neófitos, Deleuze muestra que desde que se ponen conjuntos en correlación exacta, se obtienen funciones, y se puede decir, que el sabio científico hace ciencia. Es el inventar funciones que puede dar paso a un descubrimiento. El descubrimiento existe, dice Deleuze, "pero no es por él que se pueda definir una actualidad científica como tal". Si se considera que el descubrimiento "es la observación novedosa u original de algún aspecto de la realidad, de un fenómeno natural", se puede comprender, como lo expresó el escritor francés Marcel Proust (1871-1922) que "el verdadero descubrimiento no consiste en salir a buscar nuevos paisajes, sino en tener nuevos ojos" (Auzias \& Labourdette, 2008, p. 23). La actualidad científica parece entonces evocar la idea del astrónomo Vera Rubín: "la ciencia avanza mejor cuando las observaciones obligan a cambiar las ideas preconcebidas” (Koupelis, 2011, p. 256).

La idea deleuziana del científico como artista se remonta al político, filósofo y escritor romano Marco Tulio Cicerón (106 A.C - 43 A.C) (Stone, 2005, p. 7) 
quien nos legó la idea que "el arte nace de la observación y la investigación nace de la Naturaleza”. Luego, Louis Pasteur (1822-1895), químico francés, agregó "cuando nos referimos a la observación, el azar sólo favorece a las mentes preparadas". Unas mentes 'dispuestas', 'maduras' se unen a la idea de KarlPearson (1987-1936); este matemático inglés afirmó que "todos los grandes científicos han sido, en cierto sentido, grandes artistas; el hombre sin imaginación puede recoger hechos, pero no puede hacer grandes descubrimientos".

Deleuze habla entonces del acto de creación. Pero ¿qué pasa con la noción de creación? Sabemos que la palabra 'creación' viene del verbo transitivo activo latín creare, que alude la acción y el resultado de crear; del sánscrito 'kre' que quiere decir hacer. Este vocablo da origen al vocablo latín creat-o, creación, formado por el sufijo - ción que indica acción y efecto de crear; a creador, cuyo sufijo - dor designa al agente, el que crea; creatividad, con el sufijo - dad que muestra la cualidad de crear; creativo, con su sufijo - tivo, indica la capacidad de crear. Las acepciones de esta palabra pueden aclarar el uso de los vocablos acto y creación a la vez en su pregunta. Los diversos diccionarios definen el término creación a partir de tres acepciones de sentido: acción, cosa creada, nombre propio; es decir, una palabra que puede significar hacer, pintar, producir algo, establecer, instituir, criar, crear de la nada, dar existencia a una cosa, realizar actos de habla, elaborar.

Esta polisemia permite, entonces, ver la utilidad de la postura deleuziana al ajustar la acción al acto y la producción a la creación. De esta manera, en este estudio, "la producción de una obra artística o de cualquier otra cosa que exige la participación del ingenio en su concreción, se denominará creación" (Definición ABC, 20072015, p. A).

La utilidad de la noción del acto de creación de Gilles Deleuze en el campo específico de la formación en lenguas extranjeras, se vió, entonces, en la acción de hablar y escribir en la lengua extranjera, que nace de la necesidad del docente de comunicar algo, una idea, un concepto, un proceso, un método de hacer algo que se produce en francés y, de comunicarse al realizar actos de habla concretos para producir un discurso pedagógico sobre un objeto, una obra, un libro de enseñanza; este objeto producido o creado o realizado o fabricado crea, a su vez, una 'territorialidad' y una 'temporalidad' en el contexto de la reintroducción del francés en Colombia. El maestro de lenguas extranjeras quiere con su acto de creación comunicar y compartir con el resto de pares académicos y nuevos alumnos o estudiantes del francés, su creación. 


\section{LA INVESTIGACIÓN Y CREACIÓN}

El verbo transitivo e intransitivo "investigar" proviene del latín in (en) y vestigare (hallar, inquirir, indagar, seguir vestigios). Estos significados conducen al concepto de 'descubrir o averiguar alguna cosa, seguir la huella de algo, explorar'. De esta formación etimológica, se desprenden dos acepciones del vocablo 'investigar': "hacer las diligencias necesarias para descubrir algo"; "profundizar en el estudio de una disciplina". El acto de investigar puede ser de diversos tipos, desde la curiosidad de los objetos de la natura con los cuales se amplía el horizonte de lo conocido hasta "la investigación científica con propiedades de eficacia en su procedimiento reflexivo, sistemático, controlado y crítico con el fin de descubrir o interpretar los hechos o fenómenos, relaciones o leyes" de un ámbito de la realidad (Grajales G. , 2000, pp. 1-2).

Investigar es, también, entendida como la búsqueda de la verdad. Hoy, la verdad es cambiante, es el resultado de un nuevo descubrimiento. Esto conduce al reconocimiento de la necesidad de indagar algo nuevo por aprender (Vyhmeister,1989) (Grajales G. , 2000, pp. 1-2).

Con esta descripción del término investigación, se puede entender la postura de Deleuze cuando habla de hacer ciencia. Parte de la afirmación de que "hay función" cuando se establece "correspondencia exacta al menos [de] dos conjuntos". Para él, la noción de base de la ciencia (...) es la de los conjuntos"; un conjunto, continúa él en su conferencia, "es completamente diferente a un concepto". Cuando "se ponen conjuntos en correlación exacta, se obtienen funciones, y se puede decir, yo hago ciencia" (Deleuze, 1987, p. 2).

Ahora bien, ¿qué hay en común entre la investigación y la creación? Es la necesidad de conocer algo nuevo que se presenta ante nuestro mundo sensorial que reclama ser comprendido en tanto que deseamos saber qué es verdad. Para Deleuze, es el tiempo-espacio el límite común "a todas esas series de invención de funciones, de bloques movimiento-duración, invenciones de conceptos, etc." (Deleuze, 1987, p. 2). El investigador y el creador conocen sus fronteras y dan lugar a "hablar del nombre de su creación" o de su producción; lo que es común a los dos es el hablar de su obra. Deleuze afirma que "no hay lugar entre ellos de hablar de la creación pues es algo solitario". 
Deleuze constata que el tiempo-espacio es entonces lo común entre el investigador y el creador y lo ilustra en el ámbito del cineasta. Al presentar el tratamiento del tiempo y espacio en la producción cinematográfica de algunos cineastas como Robert Bresson (Francia 1901-1999), Akira Kurosawa (Japón 1910-1998) y Hans-Jürgen Syberberg (Alemania 1935-), Deleuze analiza que cada creación cinematográfica nace de una idea que es necesaria develar a otros, la cual se ha fabricado con diversos elementos que difieren de otras producciones. Un objeto, una parte del cuerpo, un grupo de personas y un desierto, toman lugar en la tierra en "su hora y en su lugar". Estos se focalizan por la cámara desde diversos ángulos y posiciones de la máquina filmadora, de manera que la historia sucede en un aquí y en un ahora.

Esta idea de tiempo y espacio se puede ver también en el acto de investigación académica; el estudioso de algo se ubica en un tiempo y en un espacio en tanto límite frente a otros investigadores. Y ¿qué es lo común entre el creador y el investigador? Es también probar que "tener una idea" en algo no es del orden de la comunicación ni de la información en el sentido que Deleuze demuestra en su conferencia:

(...) lo que hablamos es irreductible a toda comunicación. (...), ¿qué quiere decir? (...) en un primer sentido, que la comunicación es la propagación y la transmisión de una información. ¿Y qué es una información? Una información es un conjunto de palabras de orden. (...) informar es hacer circular una palabra de orden. (...) se nos comunica la información, (...) se nos dice aquello que es conveniente que creamos. O (...) que creamos; pero que hagamos que lo creemos, no se nos pide que creamos, se nos pide que nos comportemos como si creyéramos. Esto es la información, la comunicación, e independientemente de estas palabras de orden y de la transmisión de las palabras de orden no hay comunicación, no hay información. Lo que nos lleva a decir que la información es exactamente el sistema de control.

De esta explicación de Deleuze, se infiere que la información es el "sistema controlado de las palabras de orden" que tienen lugar en una sociedad dada. Esta postura deleuziana abre la perspectiva de pensar que el acto de creación que da nacimiento a una obra de "arte", a una "producción" de algo es del orden de la resistencia a dicha información de control en una sociedad disciplinada. Es eficaz una información o comunicación o una contra-información cuando se convierte en 
acto de resistencia a la información de control. Por lo tanto, para Deleuze "la obra de arte no es un instrumento de comunicación, porque no contiene la mínima parte de información". Entonces, la obra hace resistencia a la información y a la comunicación. Y concluye, "el arte es laúnica cosa que resiste a la muerte" (Deleuze, 1987, pp. 5-6).

\section{ENSEÑAR Y APRENDER FRANCÉS, UN LLAMADO A UN PUEBLO COLOMBIANO QUE TODAVÍA NO EXISTE}

Desde el comienzo del segundo milenio, 2000, el acto de resistencia a la muerte de la investigación en las ciencias humanas ha cambiado. Esta resistencia es contra "la repartición de lo sagrado y lo profano", afirma Deleuze. Es un acto humano y artístico. Es el grito en música, es la lucha corporal y mental en la vida de los hombres. La "relación entre la lucha de los hombres y la obra de arte es la afinidad fundamental entre la obra de arte y un pueblo que todavía no existe". Para Deleuze "no hay obra de arte que no haga un llamado a un pueblo que no existe todavía". (Deleuze, 1987, p. 6). Y para este estudio, ese llamado a un pueblo que no existe todavía es el pueblo que hable otros idiomas además del inglés como lengua extranjera en nuestro país.

En la primera década del siglo XXI, se ha incluido la noción de creación en la acción investigativa sobre la metodología de las lenguas extranjeras como lo señala Cauquelin (2007) : "en estas últimas décadas, el sentido de la actividad artística se ha visto dirigirse a nuevas pistas de reflexión con respecto a la pregunta metodológica, en razón al deseo de los investigadores-creadores de elucidar por sí mismos el modo de la obra uniendo teoría y práctica; concepto y experiencia " (Laurier \& Lavoie, 2013, p. 295).

La idea de diseñar un manual de aprendizaje del francés FLE demanda una investigación teórica sistemática para establecer la serie de relaciones y conjuntos del sistema del idioma con el cual se van a crear textos e imágenes, según la naturaleza linguiística y estética de ambas materias de creación. Laurier \& Lavoie afirman que no existe separación fundamental entre la teoría y la práctica ya que la investigación en el campo del Arte apunta a hacer visible una parte de la teoría en la incorporación y en el centro del proceso de creación como en el objeto de arte, resultado de la investigación misma. (Laurier \& Lavoie, 2013, p. 298) 
La idea de la "investigación en creación" se asocia según Schön (1994) a la "reflexión sobre la acción”. Esta idea de investigación-creación se basa en la "unión entre el sujeto y el objeto"; este acto de resistencia no observa distancia entre el investigador, el practicante y el artista, porque es ella la que se encuentra en la alusión a lo que debe ser un docente de lenguas extranjeras frente a su deber ser en el salón de clase por cuanto él está en el lugar y a la hora del entorno del niño. (Laurier \& Lavoie, 2013, p. 298)

Esta afirmación permite ver que la investigación en creación puede ser posible si los creadores de material didáctico establecen articulaciones e integran la reflexión sobre el ser, la epistemología de ese conocimiento particular y la metodología necesaria que hacen parte del material didáctico creado.

Selon (Laurier \& Lavoie, 2013, p. 299) :

La question ontologique fait référence à la nature de l'objet (soit l'œuvre d'art ou le processus de création, de production ou de recherche qui soustend l'œuvre), la question épistémologique repose sur les formes de connaissance et de compréhension ancrées dans la pratique artistique. (...), et la question méthodologique aborde l'ensemble des méthodes et des modes appropriés à la recherche en création utilisées par tout chercheur-créateur.

Toda representación en esta metodología de la investigación en creación se entiende como la correspondencia entre "un conjunto más o menos consciente, organizado y coherente de elementos cognitivos, afectivos y del campo de valores con respecto a un objeto particular" (Garnier \& Sauvé, 1999, p. 66). Los creadores del material didáctico encontraron entonces "elementos conceptuales, actitudes, valores, imágenes mentales, connotaciones, asociaciones", entre otros aspectos, que designaron un universo simbólico, culturalmente determinado, donde se forjaron las teorías espontáneas, las opiniones, los prejuicios, las decisiones de acción, etc., para dar cuenta del contexto intercultural del objeto creado.

El estudio de la investigación en creación es, entonces, una disciplina amplia, que introduce nuevos modos metodológicos para animar la pedagogía de las lenguas. Las etapas de esta metodología ayudaron a crear el producto final llamado "Vive la joie en français" adaptado a esta nueva "tentativa" o "acto de resistencia" didáctica de investigación y creación para el pueblo que aún no existe. 


\section{LA CREACIÓN DE MATERIAL DIDÁCTICO}

La producción de material didáctico intercultural y contextualizado en el ámbito regional boyacense colombiano constituyó ese 'acto de resistencia a la muerte' del francés en Colombia. Esta resistencia de algunos francófonos, futuros docentes en el ámbito de la educación básica primaria y secundaria, nació de la necesidad de trabajar mancomunadamente en la creación de libros de enseñanza y de lectura del francés para ofrecer una posible solución a la escasez de este material en las instituciones educativas y porqué no, de los practicantes de francés en la unidad de formación de lenguas extranjeras y de idiomas de la UPTC, si tenemos la fortuna de contar con la voluntad política académica.

Como dice Deleuze, "un libro es un pequeño engranaje de una maquinaria exterior mucho más compleja". [Su] "creador es un ser que trabaja por gusto". Así es el fututo docente investigador en creación de materiales didácticos en francés quien ha escuchado la "idea ya vista de antemano" "en el dominio determinado" de la formación docente de las lenguas extranjeras. Esta idea de la materia de contenido se transformó en materia de creación en estos jóvenes investigadores al observar el territorio de las instituciones educativas, lugar de la fuente del tema de investigación en creación.

Molina \& Molina (2012) establecieron las bases teóricas y metodológicas para que la idea de un "manual de lengua" pasara de ser una materia de contenido a una materia de creación. La conceptualización del proceso de hacer un libro texto partió desde pensar el titulo, la presentación de los autores, la organización por capítulos o sub-capítulos con las lecciones respectivas y el material de apoyo auditivo, audiovisual, ilustraciones, imágenes o fotos.

(Lemeunier-Quéré, 2003) afirma que el desarrollo de competencias lingüísticas y comunicativas es más eficaz si se cuenta con un material didáctico complementario, como el libro. Este objeto creado logró materializar cuatro objetivos: desarrollar una competencia particular, comprensión y expresión oral y escrita, reforzar una zona de la competencia lingüística, léxica, fónica, gramatical, proponer actividades a partir de objetivos específicos o profesionales para el uso de la lengua extranjera, dar información de aspectos culturales relacionados con la lengua de aprendizaje y, preparar exámenes para la obtención de un certificado de idioma extranjero. 
El proceso de creación del manual de idioma resultó del estudio etnográfico del público al cual va dirigida dicha obra. Este primer paso determinó la composición de las unidades didácticas, sus lecciones y las actividades que contribuyen a la construcción de conexiones y relaciones entre los sujetos con el conjunto del método según las perspectivas didácticas aplicadas: de acción, intercultural y escuela nueva, para animar el proceso de aprendizaje de la lengua extranjera.

Los creadores tomaron en cuenta la dimensión ontológica de los alumnos (Molina $\&$ Molina, 2012, p. 158) la cual se manifestó en una matriz del contenido que se modificó a medida que se avanzó en la creación de la obra o producto final; el orden de la secuencia temática y lingüística varió según la necesidad de introducir la enseñanza de lo cultural. Veamos las matrices elaboradas en el año 2012 y en el año 2014 que definieron la obra creada: 


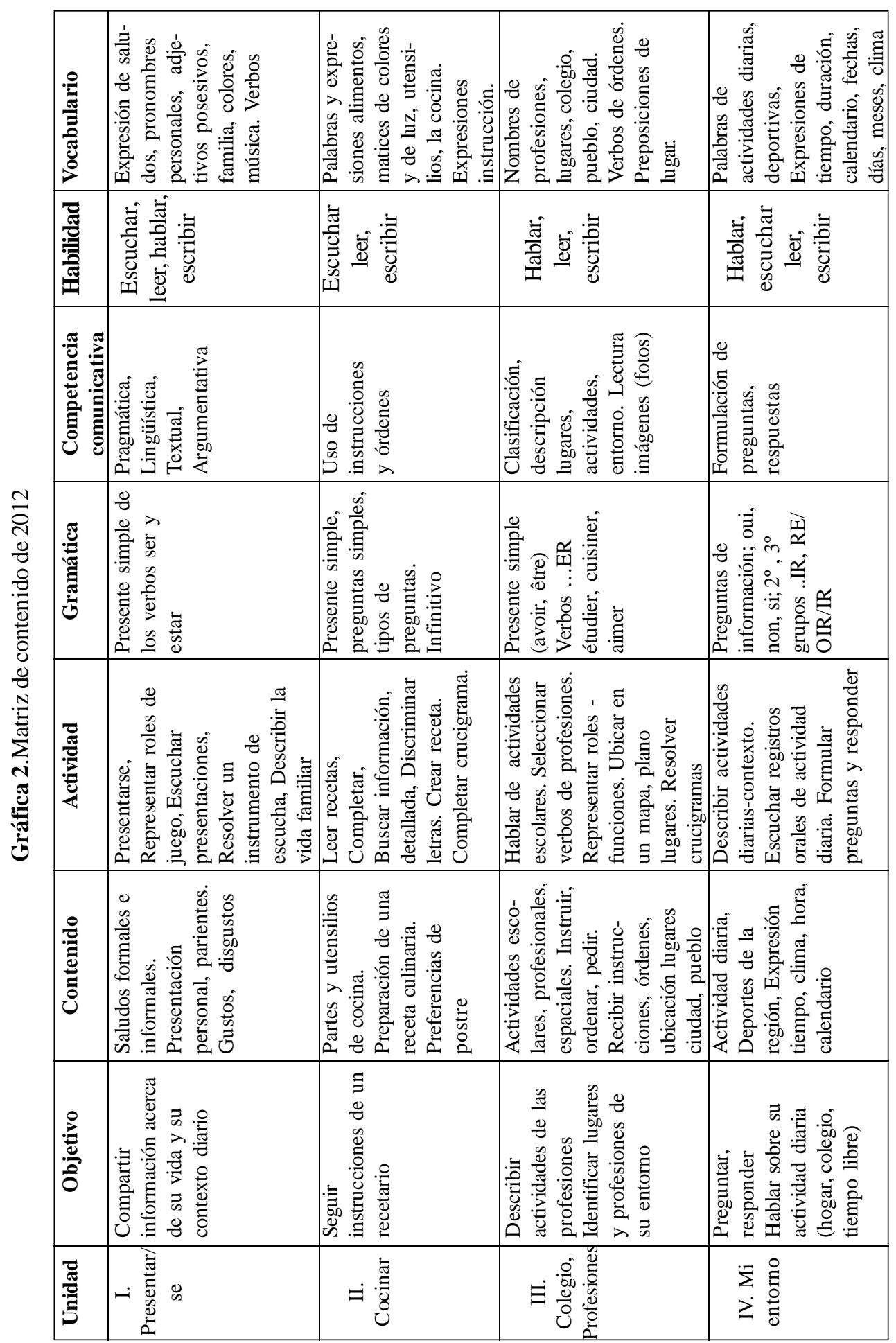

186 Cuestiones de Filosofía No. 19 - Vol. 2 Año 2016 ISSN 0123-5095 Tunja-Colombia 


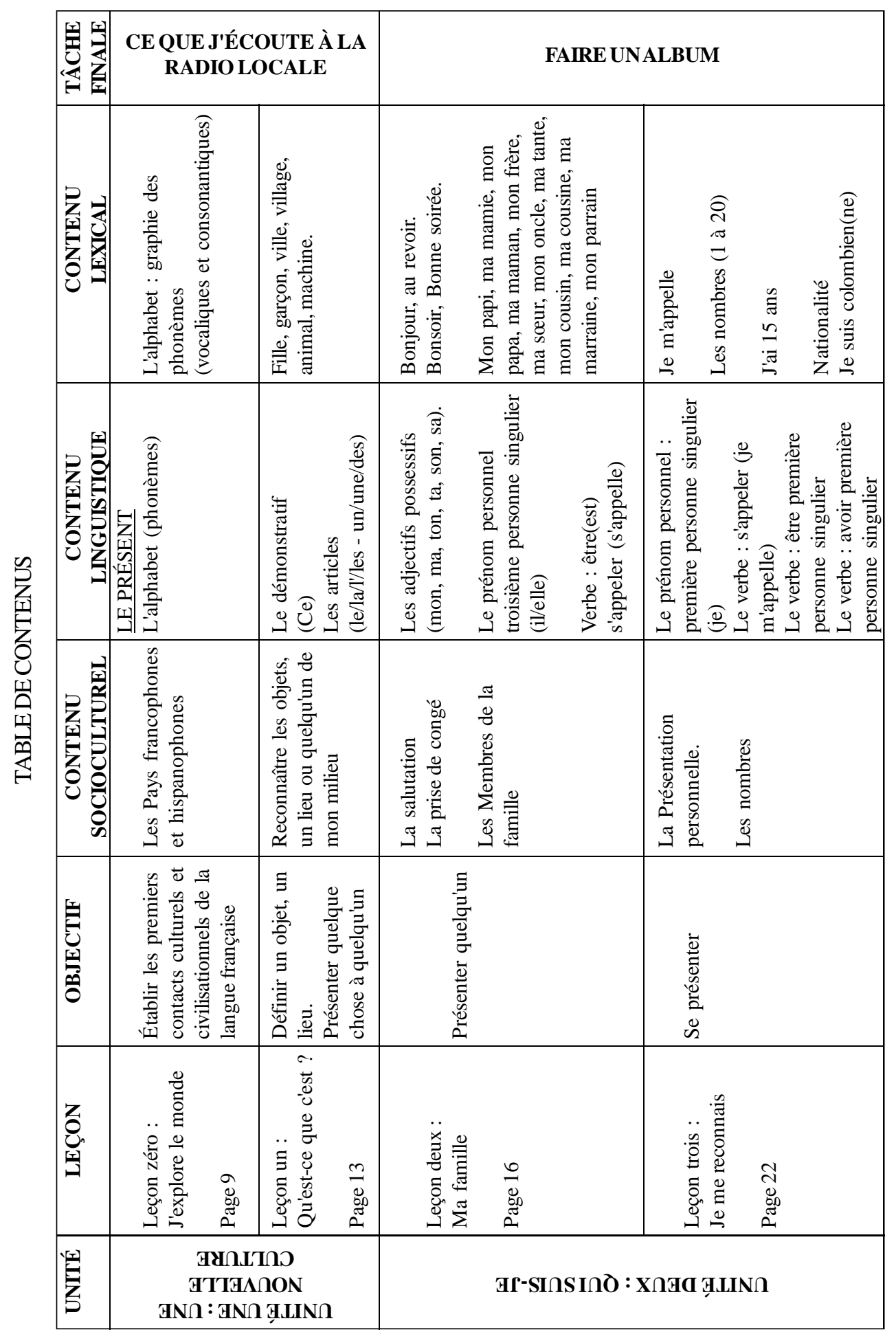

La noción de creación deleuziana en la elaboración de material didáctico en lenguas extranjeras 187 Martha Pardo Segura - p. 173-202 


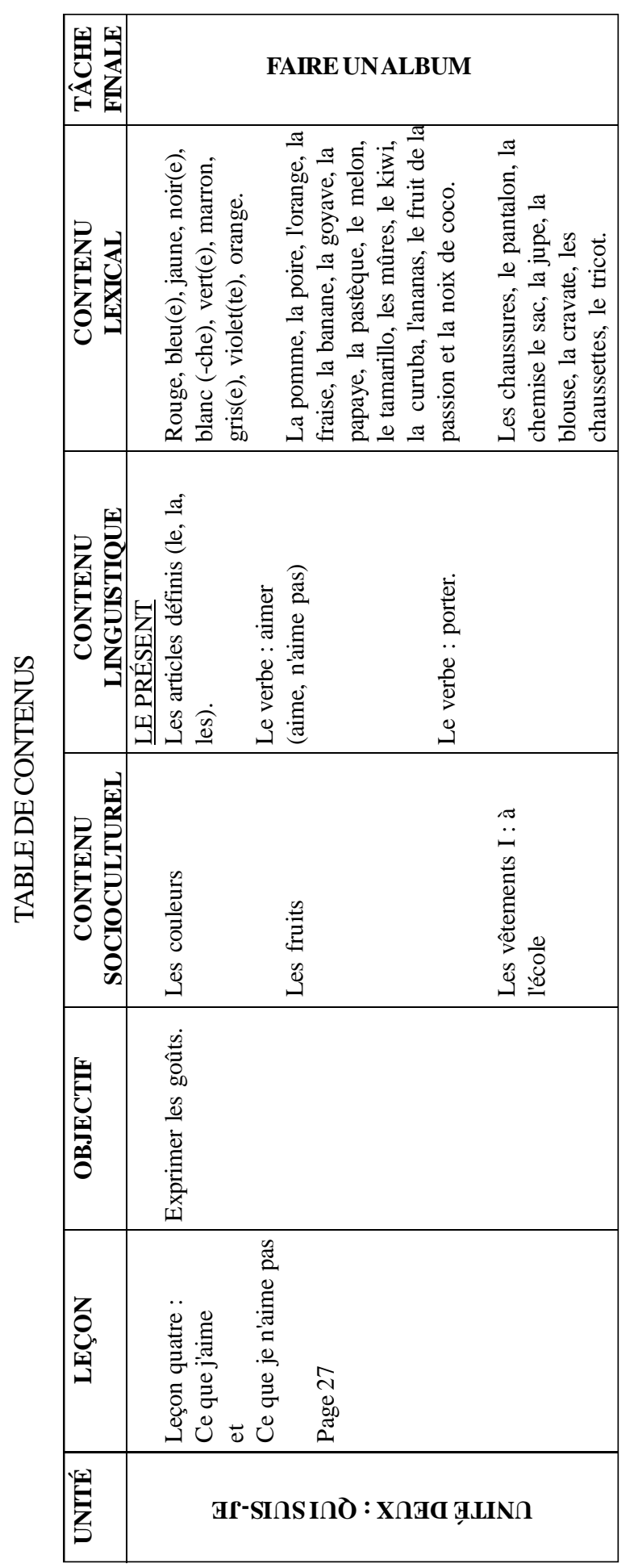

188

Cuestiones de Filosofía No. 19 - Vol. 2 A ño 2016 ISSN 0123-5095 Tunja-Colombia 
Cada unidad se compuso de series de actividades pedagógicas autónomas de carácter intercultural e interdisciplinar; la geografía, las matemáticas, la ecología apoyaron la creación de procesos de aprendizaje natural del idioma que nace de una necesidad de comunicar lo propio.

\section{Imagen $\mathrm{N}^{\mathrm{o}} 1$}

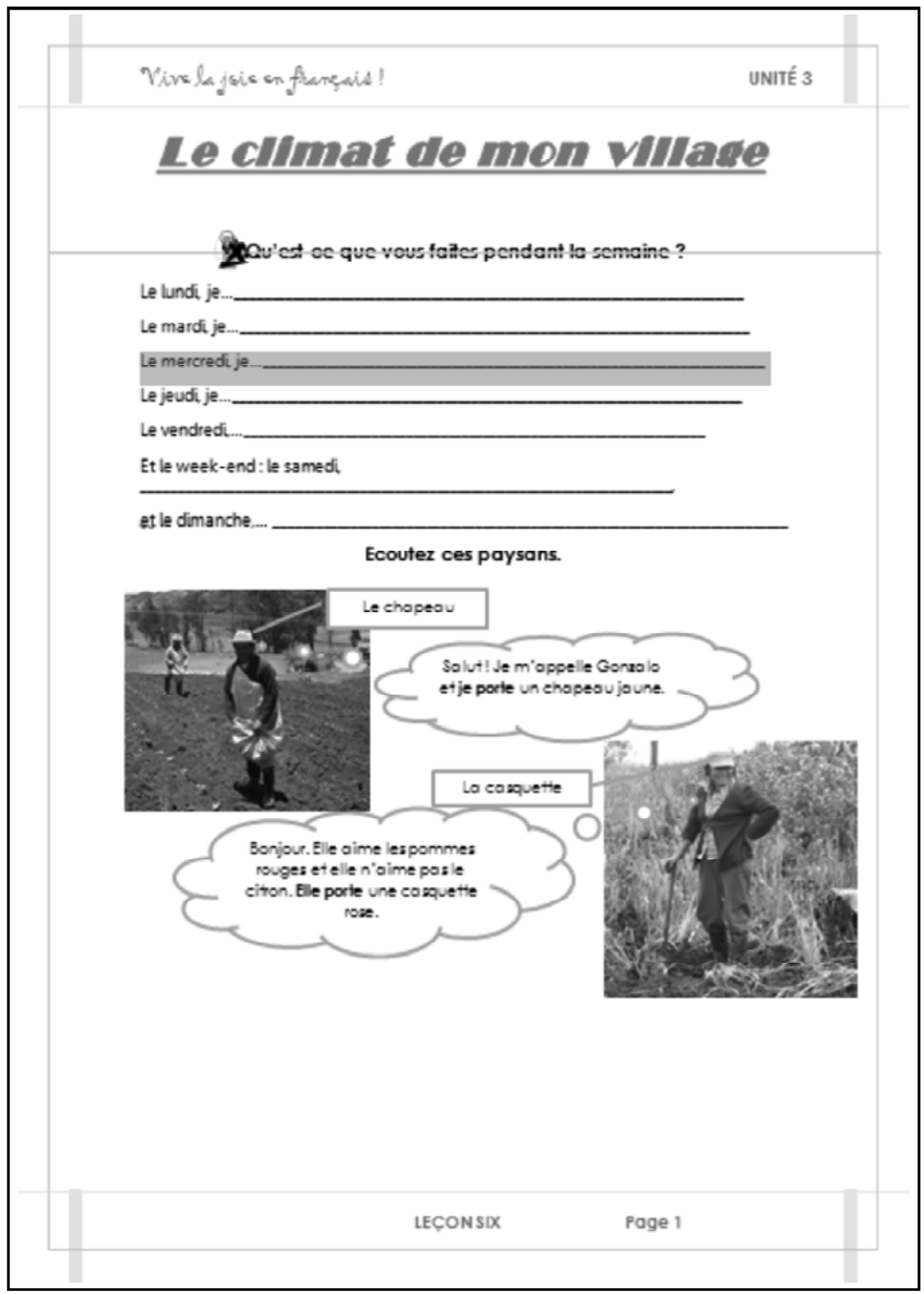

La noción de creación deleuziana en la elaboración de material didáctico en lenguas extranjeras Martha Pardo Segura - p. 173-202 
Los temas culturales y de civilización de los países francófonos se diseñaron en la sección llamada “exploración cultural", lugar en donde la información recupera el contenido lingüístico aprendido. Esta etapa del método de aprendizaje del idioma activa la necesidad de comunicar y comunicarse para establecer las relaciones sociales fundamentales a la producción oral. Para lograr la comunicación, las actividades elaboradas conducen a hacer tareas puntuales de lenguaje y de interacción social.

Imagen $\mathrm{N}^{\mathrm{o}} 2$

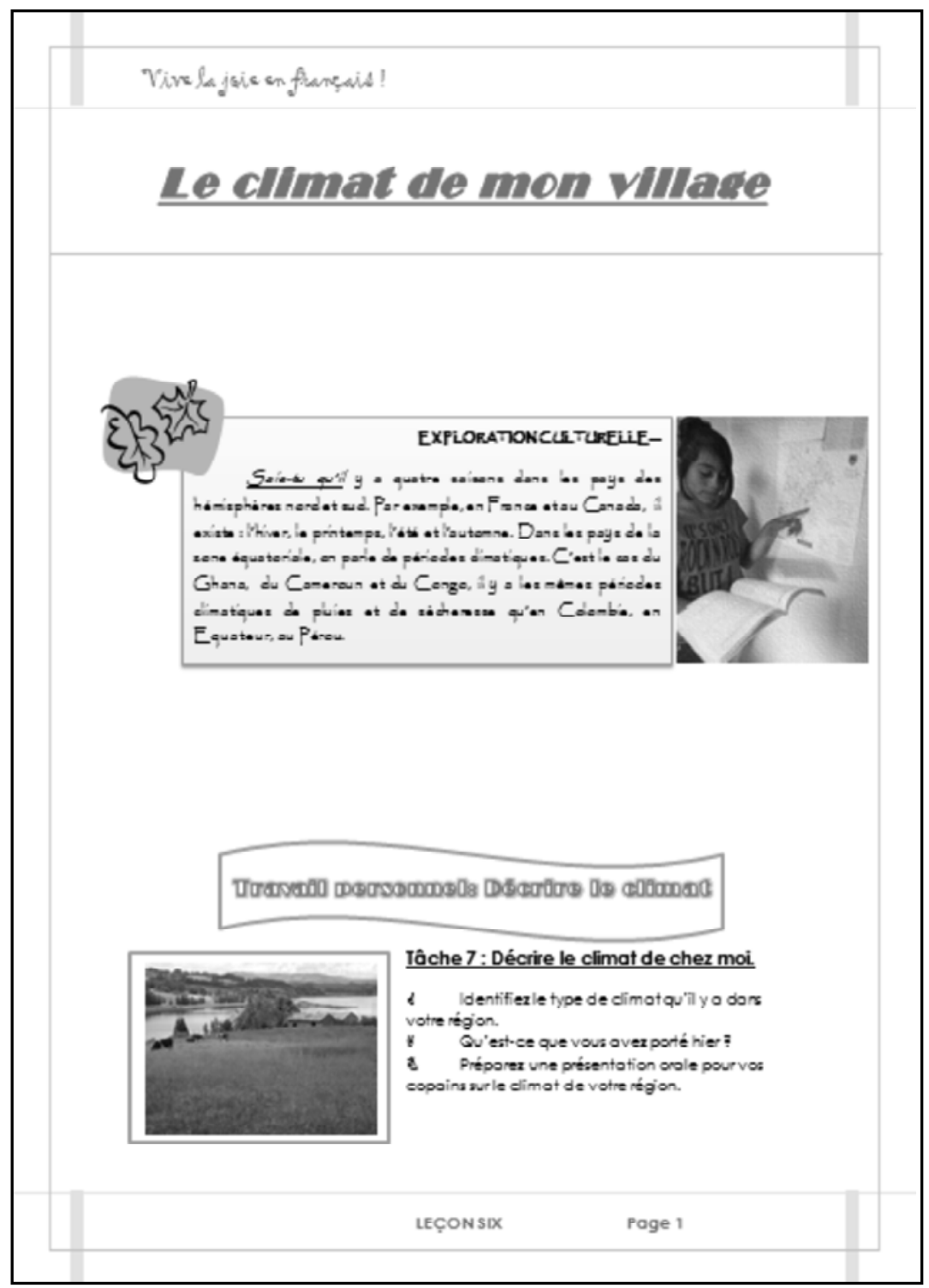


La investigación en creación de material didáctico de lenguas extranjeras prosiguió el método que según la Guide méthodologique de l'élaboration des manuels scolaires, (Seguin, 1989, p. 7) se planteó como la edición de un libro escolar. Seguin escribe: "la edición de un libro escolar es una actividad muy compleja que exige múltiples competencias en la medida en que ella realiza el diseño de la forma de la obra. Requiere de examinar numerosos elementos de orden visual, gráfico y material. La composición de los textos debe basarse en fenómenos como el proceso de lectura, la lisibilidad, la percepción y la memorización visual’. Veamos la página del contenido programado en el cual se establecieron competencias de comunicación y el objetivo de la lección 0.

\section{Imagen $N^{0} 3$}

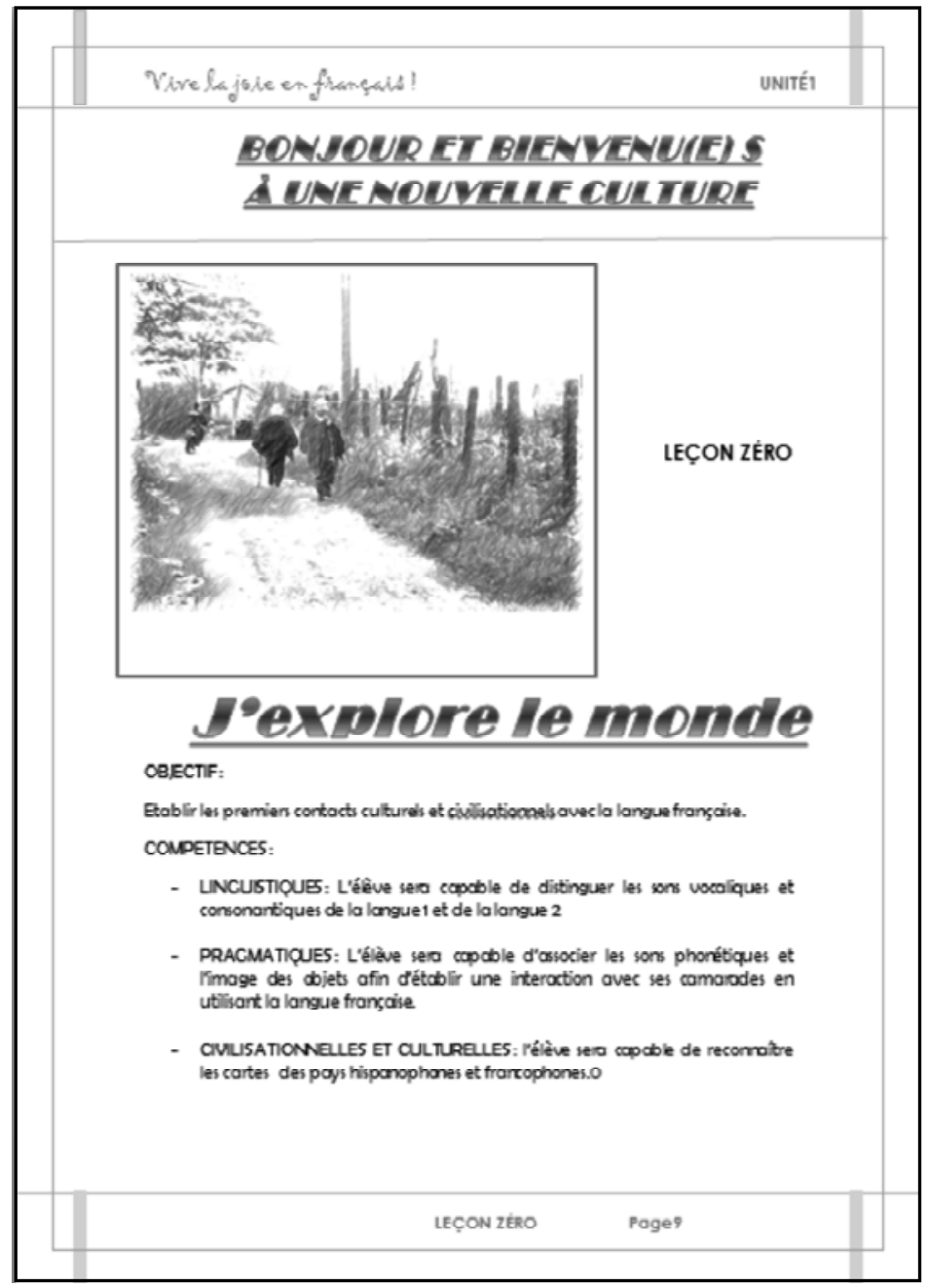


La creación de la unidad didáctica dependió de la coherencia entre los campos y elementos didácticos y conceptuales que son numerosos y heterogéneos. (Puren, 2011, p. 13). Se determinó diseñar una secuencia de actividades para trabajar con diferencias que intervienen en el proceso y evolución de los objetivos establecidos para el proceso de aprendizaje por parte del alumno. La evolución de la idea de crear un manual de francés, propuesto por Molina \& Molina en 2012 (Gráfica 1) se estableció en 2012 en una síntesis de dimensiones ontológicas de los alumnos participantes de la experiencia, para construir la concordancia de los temas y de las actividades; tanto los contenidos temáticos como lingüísticos y culturales se validaron por (Daza Hurtado \& Muñoz Talero, 2014) para la creación consensuada de unidades y lecciones. (Gráfica 2)

Gráfica $\mathrm{N}^{\mathrm{o}}$ 1.- Esquema de dimensiones ontológicas de los alumnos.

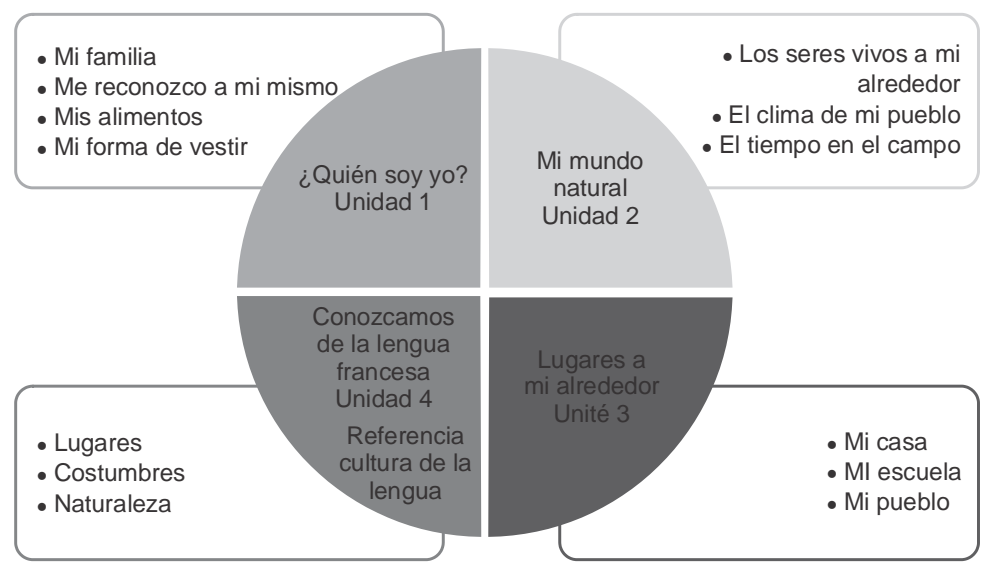




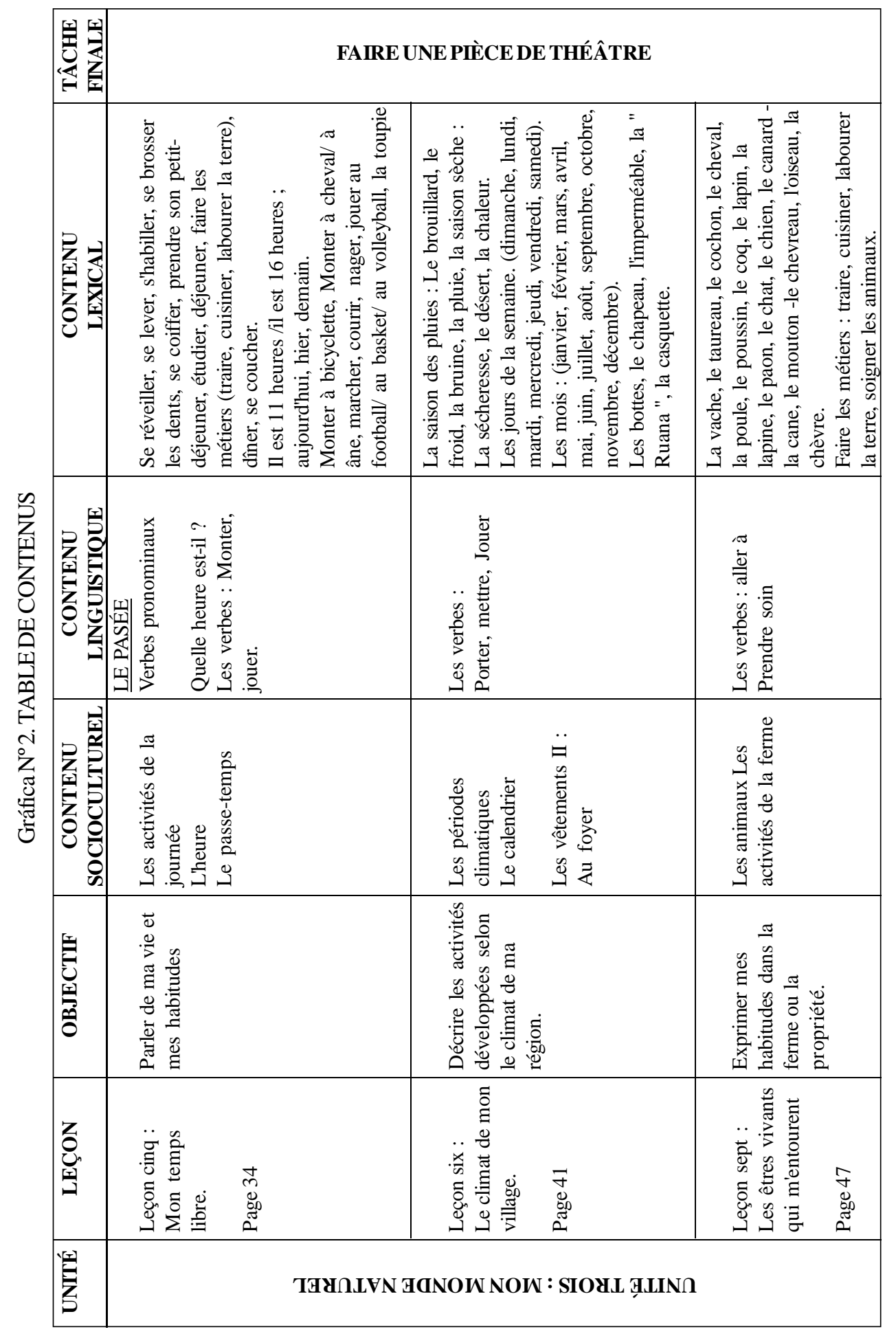

La noción de creación deleuziana en la elaboración de material didáctico en lenguas extranjeras Martha Pardo Segura - p. 173-202 


\begin{tabular}{|c|c|c|c|c|c|c|}
\hline \multirow{2}{*}{ 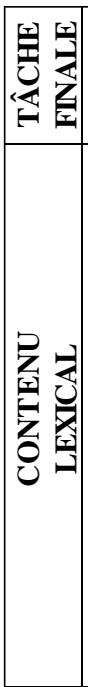 } & \multicolumn{6}{|c|}{ LA GALERIE D'ART : L'HISTOIRE DU VILLAGE } \\
\hline & 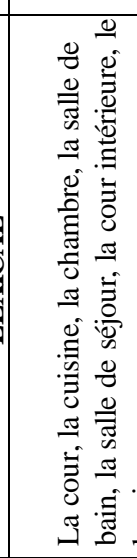 & 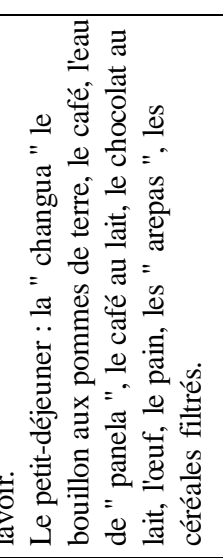 & 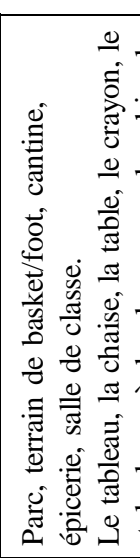 & 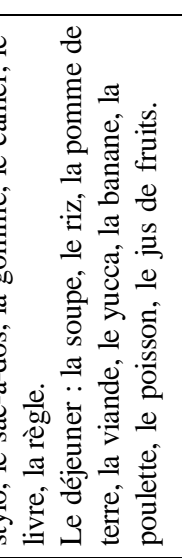 & 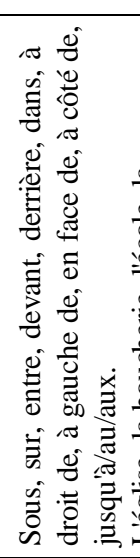 & 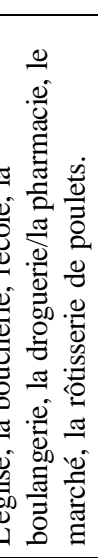 \\
\hline 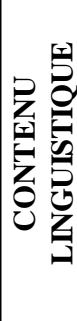 & 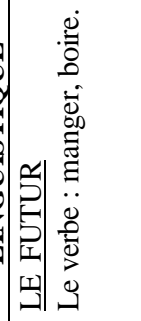 & & 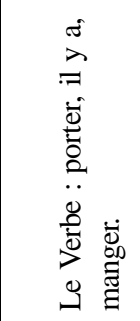 & & 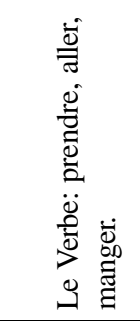 & 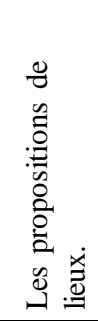 \\
\hline 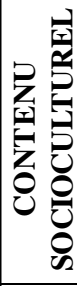 & 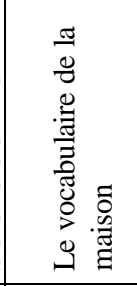 & 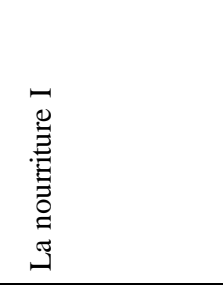 & 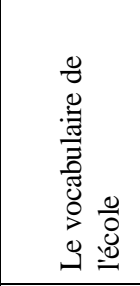 & 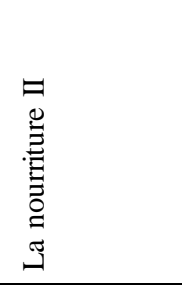 & 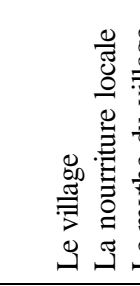 & \\
\hline 琴 & 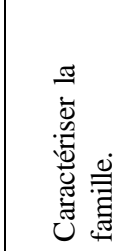 & & 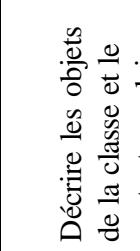 & & 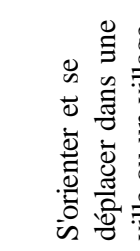 & \\
\hline $\begin{array}{l}z \\
0 \\
0 \\
\text { 岳 }\end{array}$ & 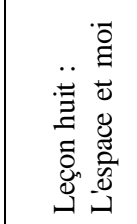 & $\begin{array}{l}\Delta \\
0 \\
0 \\
0 \\
\approx \\
\approx\end{array}$ & 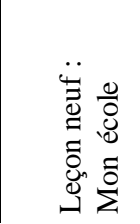 & 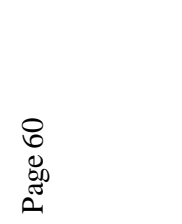 & 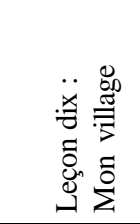 & $\begin{array}{l}8 \\
8 \\
\mathbb{8} \\
\approx \\
\approx\end{array}$ \\
\hline 资 & & IOW HC & 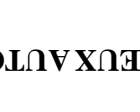 & [ : HYLVAC & IJINO & \\
\hline
\end{tabular}


Para la elaboración de nuevo material didáctico los investigadores docentes expresaron la necesidad sentida de siete aspectos que fijaron basados en la postura de Deleuze. Precisaron a) la ausencia de manuales en los establecimientos educativos a pesar de ser mencionado en el programa oficial de lenguas extranjeras, pero que no está disponible en el mercado ni en las instituciones oficiales de educación; b) la penuria de manuales que correspondan a la particularidad linguiística en el caso de francés lengua extranjera y lengua segunda o a la edad de los alumnos; c) la obligación de remediar los problemas que el manual de uso presenta, por ejemplo la evidente inadecuación de la progresión lingüística y temática según el nivel de aprendizaje de la lengua extranjera, el desinterés de los alumnos por los temas, el etnocentrismo, lo inapropiado de las actividades, el desuso de los contenidos y el costo; d) la necesidad de contextualizar el aprendizaje del francés o de darle un color local ; e) la voluntad de desarrollar un "tratamiento multimedia" que aúne a actualizar la movilización de todos los sentidos, la variedad de soportes y de temas, la valoración de las comunicaciones y el desarrollo cognitivo, la autonomía del público, la apertura sobre el mundo, para descubrir, indagar y comprender la lengua mientras que se construye sentido;f) las ganas de complacer a su público y de disfrutar con esta investigación-creación; g) la falta de seguimiento y de invertirse en su trabajo de otra forma diferente a la enseñanza pura y simple.

La relation entre la noción del acto de creación de Gilles Deleuze con la metodología de investigación cualitativa se constató en centrar la resistencia ante manuales que han ofrecido vidas humanas límpidas en un mundo abstracto de bienestar total. El enfoque de la investigación cualitativa de tipo etnográfico permitió así mostrar con la descripción de la vida real y del comportamiento del actor social en su medio: caminatas de dos horas para llegar a la escuela, oferta de una comida en la mañana, poco acompañamiento de padres o familiares a la llegada de los niños al hogar, entre otros. De las cuatro etapas explicadas en el proyecto investigativo de la etapa I, Processus de création d'un manuel d'apprentissage du français à l'école de la zone rurale du département de Boyacá”, los autores desarrollaron dos de 2012 a 2013: etapa I, la fundamentación teórica y pedagógica; etapa II, la ruta del proceso de recolección de la información etnográfica para elegir temas del contexto rural. El último proyecto de 2013 a 2015 se ocupó de tres etapas: etapa III, traducción y adaptación del castellano al francés del corpus recolectado original; etapa IV, diseño de actividades pedagógicas apoyadas e ilustradas con el corpus visual recolectado en la etapa II y ampliado en la etapa III de la investigación; etapa IV, verificación de la correspondencia entre los aspectos pedagógicos y los fundamentos teóricos de la investigación y creación del manual Vive la joie en Français. 
Se validó la creación de actividades pedagógicas del manual de francés con la investigación acción que puso a prueba la situación sociocultural observada del modelo pedagógico propuesto por los investigadores de 2012 y 2013. Se ajustó la elaboración de ejercicios, indicaciones e introdujo imágenes o relatos complementarios. Por ello, Elliot (1993), afirma que "la investigación acción es el estudio de la situación social con la meta de mejorar la calidad de la acción" de creación del manual (Blasco Mira, 2009, p. 7). Este momento de investigación acción se organizó en cuatro etapas: la planificación, en la cual se decidió por el formato, el soporte y las actividades pedagógicas presentadas en un machote borrador; la acción de crear unidades organizadas en tres lecciones para el desarrollo de la comprensión y expresión orales basadas en los temas de la vida familiar, escolar y social para el aprendizaje intercultural; la observación de las matrices de contenidos temáticos y de los corpus de fotos, relatos, leyenda; la reflexión comparativa de las matrices dieron lugar al análisis de los defectos de la estructura secuenciada de la creación y del contenido temático y lingüístico, de los lapsus linguae de los autores, de la pertinencia de las ilustraciones con el formato y el soporte. El resultado de esta cuarta fase modificó la matriz $\mathrm{N}^{\mathrm{o}} 1$ de 2012 frente a los aspectos disfuncionales; el ejercicio práctico de la estructura de la lengua extranjera o la actividad pedagógica se ajustaron al nivel académico, a la edad de los niños, al contexto rural y a la comprensión cultural (mono-, intra-, inter-, multi-, pluri-).

\section{Conclusiones}

Dar forma creativa a actividades pedagógicas produce un objeto, manual de lengua, resultado del acto de creación, para resolver la penuria de material didáctico para la enseñanza y aprendizaje del Francés en el medio monolingüe boyacense y nacional. Este proceso investigativo se equiparó con el proceso del acto de creación propuesto por Deleuze. Los actos de investigar y de crear algo muestran que una acción pensada de antemano y que se sitúa en el actor de la idea de hacer algo, se realiza en el tiempo dado para su entendimiento. El creador de material didáctico en francés muestra que es el trabajo riguroso del artista de las Bellas Artes, aun cuando su materia es de naturaleza lingüística; la acción artística se compara con la del maestro investigador de las lenguas extranjeras. Estas materias, el lenguaje y la lengua, necesitan una expresión pictórica para resistir a la abstracción de las

palabras. Por tanto, el docente investigador es creador del corpus recolectado en los espacios y tiempos socioculturales rurales monolingües hispanófonos del niño y de los actores de su entorno familiar, escolar y social. 
El acto de buscar e indagar algo en la creación de material didáctico para lenguas extranjeras, en particular el francés, se fundamenta en las innovaciones didácticas de países francófonos para valorar el acto de creación propio de materiales inéditos bajo la perspectiva investigativa formal. Enseñar una lengua extranjera a diversos públicos en el mundo introduce los fundamentos teóricos y pragmáticos interdisciplinares e interculturales para dar respuesta a las exigencias actuales del contexto globalizado y del contexto particular de los niños del departamento de Boyacá.

Puesto que el medio educativo rural se convierte en una herramienta original y auténtica de hacer investigación formal in-situ, los participantes del proyecto constataron que es un proceso creativo desde la formulación, la ejecución y finalización del mismo porque encontraron una resolución de problemáticas educativas vividas en las prácticas docentes, como la necesidad de proveer manuales de francés por medio de la creatividad razonada que forma el espíritu creativo del maestro de lenguas extranjeras. De esta manera, los estudiantes de la asignatura, proyecto de grado, respondieron a la problemática intercultural que surge de inmigraciones y emigraciones de seres humanos en su propio país.

El proceso de crear el manual de francés FLE Vive la langue française tomó cuatro años durante los cuales se seleccionaron cuatro grandes temas contextualizados de la zona rural y urbana de Boyacá; se exploraron comparativamente los mismos rasgos o memes culturales en otras latitudes francófonas, como Quebec en Canadá, Bélgica, Luxemburgo, Suiza, Túnez, Argelia, Marruecos, entre otras espacialidades y temporalidades.

El diseño del manual en francés requirió de la creación del libro del profesor para disminuir el desconocimiento de la misma lengua por parte de los docentes que están obligados a impartir esta enseñanza sin ser formados en lengua y cultura francesas francófonas. Es también una propuesta complementaria al aporte didáctico de los docentes de las instituciones educativas donde la existencia de un profesor especializado en francés es muy remota.

El acto de investigación y el de creación de material didáctico constituyen, entonces, una reflexión sobre la combinación entre la teoría y la práctica con el fin de hacer una acción creativa basada en lo que los investigadores aprendieron en el transcurso de los estudios disciplinares e interdisciplinares. Los fundamentos teóricos linguiísticos, interculturales, pedagógicos, didácticos e interdisciplinares estudiados 
y empleados, durante este acto de investigación y de creación, ampliaron la concepción estática de la enseñanza por una más dinámica y creativa para el quehacer profesional en las clases de lenguas extranjeras.

De esto se concluye que la inclusión de medios como la fotografía pasó de ser una mera técnica de grabar momentos de vida sin función alguna, a constituirse en una postura estética para profundizar sobre la metodología de investigación en creación; ésta última apoya la creación de material didáctico contextualizado. Este acto de creación puede asociarse al entorno y fortalecer la identidad cultural apoyada por la bondad delArte. Ahora, la edición y publicación de un acto de creación como un libro constituye un momento fundamental de la creación que debe ser financiado.

A pesar de la restricción financiera, el docente creador trabaja por gusto con los medios informáticos disponibles en su hogar y de fácil acceso. Este hecho nos permite concluir que los futuros docentes de francés (FLE) han desarrollado talentos individuales de inventiva y de resistencia a las adversidades del espacio, del tiempo y de condiciones en situaciones particulares de la educación nacional. Son capaces de adaptarse eficaz y valientemente a las situaciones precarias en las zonas rurales colombianas. Ellos se unieron a la frase del médico y yogui de la India Swami Sivananda (1887-1963): "la mente es el único creador. Todo ha sido creado a través de la mente. Es completamente libre de crear un mundo por sí misma”.

\section{REFERENCIAS BIBLIOGRÁFICAS}

Achab, D. (2009). L'approche interculturelle dans l'enseignement du francais langue étrangère. Recuperado el 15 de 11 de 2013, de http://ressourcescla.univ-fcomte.fr/gerflint/Algerie8/achab.pdf

Auzias, D., \& Labourdette, J.-P. (2008). Guide de l'écotourisme. (1ère édition ed.). (N. é. l’Université, Ed.) Paris, Île de France, France: Petit Futé.com.

Blanchet, P. (2007). L'approche interculturelle comme principe didactique et pédagogique structurant dans l'enseignement apprentissage de la pluralité linguistique. 21.

Blasco Mira, J. (2009). La investigación-acción. Consulté le Septiembre 14, 2013, sur http://rua.ua.es/dspace/bitstream/10045/12090/1/ LA_20INVESTIGACI_C_93N_20ACCI_C3_93N.pdf 
Bourguignon, C. (2012). De la communication à l'action vers une nouvelle approache en didactique des langues.

Recuperé de http://roumanie.vizafle.com/files/documents/3f52b6629 c4315913001f8c2.pdf

Bourguignon, C. (2012). Profil Fle. Consulté du 06 au 20 2015. Recuperé de: https://profilfle.wordpress.com/lapproche-communicactionnelle/

Bourguignon, C. (2012). Rencontre nationale des professeurs de français (Institut français de Bucarest).

Brunes y Olson. (1991). Capítulo 1 y 2. Dans I. Ogalde Careaga, Los materiales didácticos medios y recursos de apoyo a la docencia (pp. 10-11). Trillas.

Carlo, M. D. (1998). L’interculturel. CLE International.

Conseil de l'Europe. (1998). Civilisation/culture, multiculturalisme et interculturel. Dans d. Carlo, L'interculturel (pp. 40-41). Paris: CLE.

Cuq, J. P. (2003). Le Dictionnaire de didactique du français. France: CLE International.

Daza Hurtado, O. A., \& Muñoz Talero, M. L. (2014). Mise en forme des activités pédagogiques du manuel d'enseignement du français: Recherche en création de matériel didactique. Étape 2. Universidad Pedagógica y Tecnológica de Colombia, Boyacá. Tunja: UPTC.

Definición ABC, t. (2007-2015). Recuperado el 30 de septembre de 2015, de http://www.definicionabc.com/general/creacion.php

Deleuze, G. (02 de 07 de 1987). ¿Qué es el acto de creación? (completo) Subtitulado al Español. (F. d. FÉMIS., Editor, www.losdepen dientes.com.ar, Productor, \& Los dependientes blog) Recuperado el 09 de 08 de 2013, de https://youtu.be/dXOzcexu7Ks?t=345

Díaz, L. O. (2012 de 2012). Ritornelo y Territorialidad: Trazos para una teoría de la creación en Deleuze y Guattari a partir de "Mil Mesetas". (A. V. Rocca, Ed.)

Recuperado el 14 de Junio de 2015, de Observaciones filosóficas: http:// www.observacionesfilosoficas.net/nactual.html 
François, D. (1979). L’oral, les oraux et leur grammaire. Récupéré sur Le Français dans le Monde.

Fundación Escuela Nueva. (1987). Fundación Escuela Nueva. Consultado el 10 Octubre 2013,surFundación Escuela Nueva: http:// www.escuelanueva.org/portal/es/modelo-escuela-nueva/principiospedagogicos.html

Garnier, C., \& Sauvé, L. (1999). Apport de la théorie des représentations sociales à l'éducation relative à l'environnment. Éducation relative à l'environnment, 66-77.

Grajales G., T. (25 de Marzo de 2000). El concepto de investigación. (file:///A// invesdefin.htm, Productor, \& Altiustgrajales.net)

Recuperado el 1 de Septiembre de 2015, de El concepto de investigación: http:// tgrajales.net/invesdefin.pdf

IFADEM. (2012). Livret 3: Travailler les outils de la langue: pourquoi? comment? Madagascar, Francia.

Récupéré sur http://www.ifadem.org/sites/default/files/ressources/madagascarlivret_3-travailler-les-outils-de-la-langue.pdf

IFSI Prémontré / BV / FR. (2000, Octobre). Méthodologie du travail écrit de fin d'études. Consulté le Octobre 2013, sur Les outils d'enquete: http:// www.issit.tn/userfiles/downloads/Methodologie_20travail\%20ecrit_ 20fin_20etudes.pdf

Jovic, L. (1990). Méthodologie. Retrieved Noviembre 2, 2013, from Observation: aspects théoriques et pratiques: http://fulltext.bdsp.ehesp.fr/Rsi/22/47.pdf

Koupelis, T. (2011). In quest of stars and galaxies. Mississauga, Ontario, Canada: Jones \& Bartlett Publishers.

Laurier, D., \& Lavoie, N. (2013). Le point de vue du chercheur-créateur sur la question méthodologique: une démarche allant de l'énonciation de ses représentations à sa compréhension. (U. d. Québec, Éd.) Recherches Qualitatives. La recherche qualitative dans les sciences de la gestion. De a tradition à l'originalité, 32 (2), 294-319. 
Lemeunie, V. (2001). Élaborer une unité didactique à partir d'un document authentique. Récupéré sur francparler-oif: http://www.francparler-oif.org/

Lemeunier-Quéré, M. (2003, 10 15). Créer du matériel didactique : un enjeu et un contrat. Consulté le 02 22, 2014, sur ÉduFLE: http://www.edufle.net/ Creer-du-materiel-didactique-un.html

Mariampolski, H. (2012). Qu'est-ce que la recherche ethnographique? Consulté le 04 15, 2014, sur Monde Moderne: http://www.mondemoderne.com/ french/what.htm

Marti Castro, I. (2005). Diccionario enciclopédico de educación. CEAC.

McGoodwin, J. (2003). Comprendre la culture des communautés de pêcheurs: élément fondamental pour la gestion des pêches et la sécurité alimentaire.

Consulté le 11 10, 2013, sur FAO Document technique sur les pêches: http:// www.fao.org/docrep/006/y1290f/y1290f00.htm\#Contents

Ministère d'Éducation National en France . (2005). Référentiel matériel et organisation des TICE École. Consulté le 10 et 15, 2013. Récuperé dehttp:/ /media.eduscol.education.fr/file/services/93/5/Referentiel_materiel_ et_organisation_Ecole_189935.pdf

Molina, C. Z., \& Molina, S. (2012). Processus d'élaboration de matériel didactique pour l'enseignement et l'apprentissage de Francais. Tunja: UPTC.

Negura, L. (2006, Octobre 12). L'analyse de contenu dans l'étude des représentations sociales. Consulté le Avril 10, 2015, sur Sociologies, Théories et recherches: http://sociologies.revues.org/993

ONU. (2005). Stratégies global d'élaboration des manuels scolaires et matériels didactiques. Recuperado el 14 de 11 de 2013, de Unesco.org: http://unesdoc.unesco.org/images/0014/001437/143736fb.pdf

Partoune, C. (1999, Agosto). L'approche interculturelle. Consulté le enero 20, 2015, sur Quelques idées fortes pour une pédagogie interculturelle: http:// www.lmg.ulg.ac.be/competences/chantier/ethique/eth_intercult1.html 
Puren, C. (2011). Projet pédagogique et ingénierie de l'unité didactique. Les enseignants de langues, ingénieurs de projets, $X X X(1), 11-24$.

Puren, C. (2013). De l'approche communicative à la perspective actionnelle: deux ruptures décisives. Lima, Rencontre FLE.

Seguin, R. (1989, Décembre). L'élaboration des manuels scolaires, guide méthodologique. Consulté le 28 Abril 2014.

Recuperé sur UNESCO.ORG: http://www.unesco.org/education/pdf/55_16_f.pdf

Stone, J. R. (2005). The Routledge dictonary of Latin quotations. 